\title{
A Biblioteca Nacional e o Controle Bibliográfico Nacional: situação atual e perspectivas futuras
}

\author{
National library and universal bibliographic control \\ Luciana Grings \\ Mestre em Memória Social pela Universidade Federal do Estado do Rio de Janeiro - UFRJ \\ Coordenadora de Serviços Bibliográficos da Fundação Biblioteca Nacional \\ E-mail: lugrings@gmail.com \\ Stela Pacheco \\ Especialista em Gestão da Informação e Inteligência Competitiva pela Universidade Estácio de Sá \\ Chefe da Divisão de Serviços Técnicos da Biblioteca Nacional \\ E-mail: stela@bn.br
}

\section{Resumo}

Desde que iniciou como programa da Unesco na década de 70, o Controle Bibliográfico Universal tem-se valido principalmente de três instrumentos: o depósito legal, as bibliografias e os formatos de intercâmbio de dados bibliográficos. No Brasil, a operação destes três instrumentos é de competência da Fundação Biblioteca Nacional, que encontra algumas dificuldades para dar conta das tarefas. Tais dificuldades, em sua maioria, são decorrentes de problemas estruturais e financeiros. Do mesmo modo, as dimensões do país também dificultam o atingimento do sucesso do controle bibliográfico.

Palavras-chave: Controle bibliográfico; Fundação Biblioteca Nacional; depósito legal; bibliografia nacional; intercâmbio de informações bibliográficas.

\begin{abstract}
Since its beginning, Unesco's Universal Bibliographic Control Programme has been working with three instruments: legal deposit, bibliographies and bibliographic data exchange formats. In Brazil, these three instruments are under the responsibility of the National Library Foundation, which has some difficulties to realize its tasks. Most of these difficulties are due to structural and financial problems. The dimensions of the country are also a problem to reach the complete bibliographic control.
\end{abstract}

Keywords: Bibliographic control; National Library Foundation (Brazil); legal deposit; national bibliography; bibliographic information exchange.

\section{Introdução}

O conceito de controle bibliográfico é inerente às atividades das bibliotecas, desde o início destas instituições. Embora nem sempre assim denominado, podemos delinear um começo para o controle bibliográfico juntamente com o aumento das coleções e seu controle local - efetivado pelos catálogos, instrumentos presentes desde Alexandria -, passando pelo refino da ideia com a formulação das bibliografias, e chegando ao Répertoire Bibliographique Universel de Otlet no final do século XIX. Nesta linha de tempo, as perspectivas sobre o que é 
e como realizar o controle bibliográfico foram amadurecendo e crescendo junto com as unidades de informação e a produção de materiais, impressos ou não.

Assim, além das iniciativas de controle bibliográfico especializado, segmentado por instituição ou por área do conhecimento, surgiu a ideia de criar-se um mecanismo global de monitoramento das publicações. Uma parceria entre a Unesco e a IFLA, firmada nos anos 70, iniciou o programa Controle Bibliográfico Universal (CBU), cujo principal objetivo é, em síntese, agregar as iniciativas de controle bibliográfico em níveis nacionais para formar um grande repositório global de informações bibliográficas. É evidente que, em última instância, trata-se de uma estratégia facilitadora do intercâmbio de informação, cada vez mais incrementado pela explosão das tecnologias de comunicação e informação.

Entretanto, mesmo fragmentando-se a tarefa, a complexidade não diminui. A fim de alcançar o objetivo final de cooperação entre instituições e economia de recursos, é preciso muito entendimento e esforço. Num país continental como o Brasil, as dificuldades em levar a termo o controle bibliográfico nacional são inúmeras e diversas; e é delas que falaremos a respeito ao longo deste texto. Estas reflexões foram motivadas pelo convite para participar da mesa "Controle Bibliográfico e Catalogação Cooperativa: história, conceitos, políticas, procedimentos, tecnologias", do II Encontro de Estudos e Pesquisas em Catalogação, ocorrido em Belo Horizonte nos dias 19 e 20 de agosto de 2010.

\section{Instrumentos de Controle Bibliográfico}

Como já mencionamos, o controle bibliográfico foi institucionalizado como uma iniciativa global da classe bibliotecária nos anos 70, com a parceria Unesco/IFLA no lançamento do programa CBU - Controle Bibliográfico Universal. Bibliotecas representantes de muitos países compreenderam a ideia de economia de recursos com a colaboração mútua e integraram a iniciativa. A fim de atingir seus objetivos de monitoramento da produção bibliográfica, o CBU lançou mão de algumas ferramentas já existentes no campo biblioteconômico em diversos países, como por exemplo a instituição do depósito legal e as bibliografias nacionais - que, no dizer de Campello (2006), são os instrumentos determinantes da atuação de uma Agência Bibliográfica Nacional.

Além disso, são partes indispensáveis para o sucesso do compartilhamento das informações a uniformidade e consistência dos dados fornecidos pelas instituições. Desse 
modo, os formatos de intercâmbio de dados têm sido cada vez mais estudados e desenvolvidos, com destaque para o formato MARC - Machine Readable Cataloging. Não é nosso objetivo aqui estabelecer uma cronologia desta área de estudo, mas cabe a interessante observação que o CBU foi acoplado ao programa de desenvolvimento do formato MARC da IFLA, gerando o UBCIM (Universal Bibliographic Control and International Marc Core Programme), que se manteve como um programa conjunto até seu encerramento em 2003. Posteriormente, um grupo de bibliotecas nacionais em conjunto com a IFLA e a Conferência dos Diretores de Bibliotecas Nacionais (CDNL) firmaram uma nova aliança para a coordenação e desenvolvimento dos estudos de padrões e formatos de intercâmbio de informações: o ICABS (IFLA, 2008).

\section{O Depósito Legal}

Definido como a obrigação do envio de exemplares das obras publicadas em um país para uma instituição depositária, as instruções sobre depósito legal existem não só no Brasil, mas em diversos outros países como Portugal, Espanha, Polônia e Estados Unidos. A França é a pioneira neste tipo de disposição: desde 1537 a biblioteca do Rei é guarnecida pelo depósito legal das publicações nacionais, segundo disposto na Ordenança de Montpellier (LARIVIÈRE, 2000).

No Brasil, dispositivos semelhantes existem desde 1805, quando as "propinas" obrigavam as oficinas tipográficas portuguesas a enviar exemplares de suas publicações para a Real Biblioteca. Posteriormente, com a independência do Brasil, a obrigação foi transmitida à Imprensa Régia, instalada no Rio de Janeiro; esta deveria enviar suas publicações à Biblioteca Imperial e Pública da Corte e assim permaneceu até 1907, quando o Decreto 1825 finalmente regulou o Depósito Legal no país, anunciando a Biblioteca Nacional como sua única beneficiária.

Em 2004, quase um século depois, o decreto foi revogado e substituído pela Lei 10.994. Simples e direta, a lei prevê o envio de um ou mais exemplares de toda publicação editada e/ou distribuída no país à Biblioteca Nacional. Explica que a finalidade é a de registro e guarda da produção intelectual do país, bem como a elaboração da bibliografia brasileira ou seja, em última análise, o controle bibliográfico da produção editorial em âmbito nacional. Apesar de já contar com seis anos de vigência, a lei ainda não foi regulamentada. Em janeiro 
de 2010, outro instrumento de depósito legal veio somar-se ao esforço de preservação da memória cultural nacional: a lei 12.192, que dispõe sobre o depósito legal de obras musicais na Fundação Biblioteca Nacional. Existem algumas leis de depósito legal em âmbito estadual no Brasil, como por exemplo em Santa Catarina e Piauí, mas o cumprimento destas não desobriga do cumprimento da lei nacional.

\section{Bibliografia Brasileira}

O marco inicial da bibliografia brasileira é o ano de 1886, com a publicação do 'Boletim das acquisições mais importantes feitas pela Bibliotheca Nacional', por João Saldanha da Gama (CAMPELLO, 2006). Com a promulgação da legislação do depósito legal em 1825, criou-se também a necessidade de publicação de um boletim bibliográfico que prestasse contas dos materiais recebidos em cumprimento ao decreto. O "Boletim bibliográfico da Biblioteca Nacional”, criado em 1918, sobreviveu até 1982 com o mesmo título; passou então a chamar-se "Bibliografia brasileira", e assim permaneceu até 1995 quando, por problemas operacionais, a publicação impressa foi suspensa. O último número publicado foi o v. 12, n. 4, arrolando a produção recebida no ano de 1994. Nos anos de 1996 e 1997, duas exportações da base de dados alimentada no Ortodocs - o software então utilizado pela BN - originaram duas publicações da Bibliografia Brasileira em CD-Rom, que também não tiveram continuidade. Hoje em dia, pode-se acompanhar a bibliografia brasileira através dos catálogos da Biblioteca Nacional, disponíveis para consulta através do endereço http://catalogos.bn.br.

Outras publicações tentaram também preencher o espaço existente para uma bibliografia efetivamente nacional, como as do Instituto Nacional do Livro no período de 1938 a 1972, do Sindicato Nacional dos Editores de Livros entre 1963 e 1977, e das editoras Estante e Vozes entre 1952 e 1981 - todas com alguns intervalos. Das mais duradouras iniciativas foi a da Editora Nobel, que publicou seu Catálogo Brasileiro de Publicações de 1980 a meados da década de 90, primeiramente com ampla circulação comercial e por fim restrito ao público livreiro. Além destas publicações, Fonseca (1972, p.11) chama a atenção para algumas tentativas de particulares de manter uma bibliografia; nenhuma, porém, obteve o sucesso almejado.

InCID: R. Ci. Inf. e Doc., Ribeirão Preto, v. 1, n. 2, p. 77-88, jul./dez. 2010 


\section{Formatos de intercâmbio de dados}

A preocupação com a uniformidade dos dados para intercâmbio de informações não é recente, mas teve um impulso enorme com o avanço da tecnologia e a massiva aplicação do processamento informatizado nos acervos das bibliotecas. Desde o século XIX a classe bibliotecária tem discutido regras para a descrição documental, muitas vezes sem consenso. Uma maior união em torno das mesmas regras foi conseguida com a publicação dos códigos de catalogação da American Library Association (ALA), a primeira edição em 1908 e a segunda, amplamente revisada, em 1949. Somente depois de várias discussões entre Estados Unidos e Inglaterra, e tentando aproximar-se dos Princípios de Paris (estabelecidos na Conferência Internacional sobre Princípios de Catalogação em 1961), foi que surgiu o Código de Catalogação Anglo-Americano (AACR), em 1967.

A etapa posterior foi a de criação de padrões realmente internacionais para descrição documental, sem privilegiar o foro anglo-americano de discussão. Em 1969, na Conferência de Especialistas em Catalogação de Copenhague, o primeiro passo foi dado rumo aos Padrões Internacionais de Descrição Bibliográfica (ISBD), estabelecendo-se grupos de trabalho para o desenvolvimento dos ditos padrões para diversos suportes documentais. O primeiro padrão a ser lançado foi o de monografias, dito ISBD(M), em 1971.

A criação dos ISBDs obrigou, de certa forma, a revisão e convergência das regras do AACR. Assim, em 1978, foi publicada a segunda edição do Código de Catalogação AngloAmericano, um conjunto de normas de catalogação seguido em grande parte das bibliotecas até hoje. Entretanto, o modelo revela-se paulatinamente defasado a partir da automatização do processamento técnico documental e aumento dos suportes de informação - em especial o surgimento dos suportes digitais. Nem as sucessivas revisões de 1988, 1998 e 2002 foram capazes de adequar as regras às novas necessidades das unidades de informação.

A inspiração para o novo modo de pensar a descrição documental veio das ciências da computação e da arquitetura de dados em bancos informacionais. No início da década de 90 , um grupo de especialistas coordenados pela IFLA reuniu-se para dar início aos trabalhos que culminariam com a publicação dos FRBR (Requisitos Funcionais para Registros Bibliográficos), em 1997. Os FRBR são um modelo conceitual entidade-relacionamento que procura, ao invés de definir regras práticas para como catalogar, fazer o profissional pensar sobre o item que está descrevendo e sua relação com o universo documental a que pertence. 
Foi uma grande mudança no modo de entender o processo técnico, que aproximou a teoria das instruções dos ISBDs e do próprio formato MARC, além de a tratar a descrição documental como um processo holístico.

Junto com os FRBR e sua nova perspectiva de representação descritiva, outros grupos de trabalho trataram de repensar a representação temática. Surgiram, então, os FRAD (Functional Requirements for Authority Data - Requisitos Funcionais para Dados de Autoridades) e os FRSAD (Functional Requirements for Subject Authority Data - Requisitos Funcionais para Dados de Autoridades de Assuntos). Foi o início da aproximação das áreas de catalogação e indexação, a partir de uma visão focada na comodidade do usuário em encontrar o recurso informacional desejado.

Era preciso, então, repensar a prática de catalogação. A perspectiva dada pelo conjunto dos novos requisitos funcionais sugeria que o próprio nome do código deveria ser mudado, uma vez que essa nova visão, mais global, do processo técnico exigia uma mudança de postura do profissional catalogador. Foi então que o Comitê para a Revisão do AACR2 apostou num novo nome para as regras, apontando para normas mais modernas e compatíveis com a atual diversidade de suportes informacionais: o RDA (Resource Description and Access), sucessor do Código de Catalogação, começou a ser delineado em 2006 e trouxe não só instruções para a descrição física dos itens como para a representação temática. Até o presente momento o RDA não foi oficialmente publicado. É um empreendimento incrivelmente robusto e encontra-se em fase de avaliação, mas esperamos que em breve a versão definitiva esteja disponível no mercado.

\section{Dificuldades no Controle Bibliográfico}

Como vimos no capítulo anterior, são basicamente três os mecanismos e ferramentas utilizados para o controle bibliográfico: o depósito legal, as bibliografias e os formatos de intercâmbio de dados, todos ligados à atuação das Agências Bibliográficas Nacionais que, em muitos países, são as Bibliotecas Nacionais. É o caso do Brasil, onde a Biblioteca Nacional acumula, pelo menos em tese, o recebimento do Depósito Legal, a publicação da Bibliografia Brasileira, a função de biblioteca referencial para autoridades e terminologia e a supervisão técnica da Agência Nacional do ISBN. Das funções de uma Agência Bibliográfica Nacional descritas por Campello (2006), a BN brasileira somente se exime da atribuição de ISSN 
(competência do IBICT, Instituto Brasileiro de Informação em Ciência e Tecnologia, "herdeiro" do IBBD, Instituto Brasileiro de Bibliografia e Documentação) e da confecção de fichas de catalogação na publicação (mais comumente realizadas pela CBL, Câmara Brasileira do Livro, e pelo SNEL, Sindicato Nacional de Editores de Livros).

Mesmo assim, diversas são as dificuldades encontradas para manter os serviços operando. Problemas legais, estruturais e financeiros são comuns e emperram o desenvolvimento das melhores práticas almejadas pelas equipes envolvidas nas tarefas. Vejamos, pontualmente, os principais problemas enfrentados.

\section{No Depósito Legal}

A equipe da Divisão de Depósito Legal é composta, atualmente, por cinco pessoas, das quais apenas uma é bibliotecária e somente duas são servidoras da Casa. Rotineiramente, a DDL recebe cerca de 150 volumes por dia, contabiliza estes volumes e encaminha para os setores competentes. Além disso, é encarregada do contato e cobrança das entidades que não cumprem o depósito, incluindo aí editoras e autores independentes. Os dados destes alimentam o Catálogo de Editores, que atualmente passa por revisão sistemática.

As atividades da DDL sofreram um incremento severo com a publicação da lei do Depósito Legal de publicações musicais, aumentando não só o número de instituições a serem contatadas como o volume de material captado, agora em outras mídias. Além do aspecto prático, já citado, existem ajustes cotidianos que vem sendo feitos à medida das necessidades, uma vez que a legislação não contemplou as reais possibilidades de execução da tarefa. Por exemplo, a lei só designa que a publicadora deve enviar duas cópias do material (do CD, por exemplo), mais uma cópia em formato digital - mas não especifica qual é o formato. Além de onerar imensamente o já exíguo espaço disponível para armazenamento, uma discussão interna está sendo desenvolvida para estabelecer qual é o formato digital ideal para guarda das obras musicais, numa biblioteca que ainda não dispõe de um data center à altura das suas competências.

Notamos que a lei das obras musicais é redundante, uma vez que bastaria a devida regulamentação da lei do Depósito Legal de 2004 para incluir não só obras musicais, mas toda uma gama de materiais cuja captação é sempre prejudicada pela falta de regulamentação. A falta deste ato, aliás, repercute principalmente na cobrança e punição dos descumpridores da 
lei, já que está prevista a sanção mas não a forma de aplicação dela - que seria resolvida com a devida regulamentação legal do dispositivo.

O formato digital das obras musicais é um ponto muito recente na pauta do depósito legal em nível mundial. Mesmo iniciativas como a da Biblioteca Nacional da Austrália, que possui uma equipe encarregada de varrer a Web capturando páginas e conta com infraestrutura suficiente para manter esse material por vezes efêmero, não tem políticas definidas a respeito da guarda de arquivos sonoros. Situação semelhante encontra-se na Library of Congress, dos Estados Unidos. A solução paliativa tem sido a cobrança do formato digital em arquivos .mp3, cuja combinação fidelidade versus compressão são o mais próximo do ideal que podemos armazenar.

A composição e o tamanho das equipes de trabalho também acabam por dificultar a execução das tarefas. Mesmo que a Divisão de Depósito Legal tivesse um número maior de funcionários, o material captado ficaria acumulado até que as etapas posteriores do processamento técnico pudessem dar conta do trabalho - que já encontra-se em estágio avançado de atraso por falta de pessoal, chegando a quase seis meses de material captado esperando por catalogação. É um efeito dominó que somente um concurso público com oferta de vencimentos melhores poderia resolver.

Apesar de contarmos com a boa vontade de muitas editoras, principalmente as de grande porte, a captação de publicações de editoras pequenas e de autores independentes é muito dificultada pela falta de publicidade quanto à legislação vigente, bem como pelo alto custo da tarifa postal que onera o cumprimento da lei. Se o porte das publicações enviadas ao Depósito Legal fosse subsidiado, se poderia esperar um maior retorno das editoras, principalmente as localizadas em regiões do país mais distantes do Rio de Janeiro. A mesma facilidade no porte poderia estreitar as relações entre a FBN e as bibliotecas públicas estaduais, beneficiárias do Depósito Legal em seus Estados (quando há essa possibilidade) e que poderiam atuar como "ramais" do Depósito Legal nacional, recebendo a produção dos Estados e encaminhando para a Biblioteca Nacional.

Os dados da Agência do ISBN também vem sendo utilizados para tentarmos mapear a produção editorial brasileira e cobrá-la de modo mais eficiente. Entretanto, mesmo estes dados tem seus pontos fracos: algumas editoras adquirem os números antes de terem a publicação pronta; outras sequer cumprem esta etapa tão importante do processo editorial, apesar da obrigatoriedade imposta pela Lei do Livro (Lei n. 10.753/03); outras ainda usam o 
mesmo número para mais de uma publicação. Resumidamente: nem o uso do ISBN, cuja prática já deveria ser corriqueira no meio editorial, é suficiente para termos um panorama fidedigno da bibliografia brasileira.

A captação de materiais digitais também é outro ponto vulnerável da atuação do Depósito Legal, já que a legislação vigente não prevê estes casos específicos. Se a equipe é insuficiente para conseguir captar todo o material impresso, como fazer para captar publicações online ou efêmeras? Algumas editoras de periódicos digitais já estão convencidas da importância de formatar suas publicações em CD ou DVD antes de enviar à BN, mas ainda assim, o trabalho de informação é grande e demanda bastante tempo. É preciso conscientização dos editores de que a exigência da formatação em mídia digital visa também a proteção dos direitos autorais e patrimoniais deles próprios. Uma vez que o material não venha formatado, a responsabilidade pela fidedignidade dos dados passa a ser da Biblioteca e este é um ônus com o qual não se pode arcar.

\section{Na execução da Bibliografia brasileira}

O mesmo problema de falta de pessoal que já citamos na equipe do Depósito Legal acomete toda a Coordenadoria de Serviços Bibliográficos da Biblioteca Nacional, responsável pelo tratamento técnico do material monográfico da Casa. Além do atraso inerente ao envio das publicações por parte das editoras, ainda temos de lidar com o acúmulo de material recebido, em muito superior à capacidade da equipe de catalogadores de iniciar o processamento técnico. Como resultado, caixas e mais caixas de material acumulam-se em ordem cronológica de chegada, aguardando a oportunidade de inclusão na base de dados e posteriores etapas (registro, classificação, indexação).

Uma outra situação grave está consumindo esforços da equipe na alimentação das bases de dados. Na década passada, a falta de servidores para trabalhar no processamento obrigou o envio de muitos materiais ao prédio II da Biblioteca Nacional, comumente chamado Anexo, para aguardarem condições mais propícias para a devida inserção no acervo. No momento, obras de recuperação do prédio e diversos outros fatores tornam o Anexo um local pouco adequado para o armazenamento destes materiais não tratados, o que nos obriga a traze-los de volta com urgência e providenciar algum tipo de processamento técnico. Atualmente, duas bibliotecárias foram designadas no setor de Intercâmbio para dar conta 
desta tarefa, uma vez que a maior parte do material foi recebida através de doação ou permuta.

Deste modo, a retomada da publicação impressa da Bibliografia Brasileira ganhou um status secundário, diante de tantos outros problemas mais prementes no cotidiano da Biblioteca. Entendemos que a disponibilização da informação online e em tempo real supre, de algum modo, o espaço deixado pela publicação da Bibliografia; por outro lado, é possível extrair relatórios internos bimestrais da alimentação da base, indexados por um campo que indica o ano e bimestre em que aquele livro foi incluído na base de dados. A despeito de todas estas dificuldades, Knutsen e Movilla Lopez (2004), em relatório da IFLA sobre as bibliografias nacionais da América Latina, aponta que o Brasil tinha um controle bibliográfico "substancial", bastante mais significativo do que muitos dos demais dezesseis países que responderam ao estudo. À época, apesar do formato impresso continuar sendo o preferido para a divulgação da bibliografia, o estudo já apontava a tendência ao investimento no acesso pela Internet.

\section{No controle de autoridades e terminologia}

Das áreas relativas ao controle bibliográfico, esta é seguramente a de atuação mais efetiva dentro da Fundação Biblioteca Nacional. Ambas as equipes são um exemplo de interoperabilidade de dados e de cooperação entre instituições, a fim de manter os mais rigorosos padrões para intercâmbio e pesquisa. Apesar de pequena, a equipe de Terminologia mantém seu catálogo inteiramente atualizado e em conformidade com o catálogo de terminologia da Library of Congress, inclusive replicando os termos no original e permitindo sua consulta no catálogo da FBN. A criação de novos termos ocorre na medida em que especificidades regionais são identificadas, e mesmo assim antes é feita uma rigorosa pesquisa de formato e de aproximação com os termos da LC, de forma a manter a mais perfeita homogeneidade possível.

Já a equipe de controle de autoridades tem à disposição um maior número de fontes para consultar, o que torna a tarefa muitas vezes mais exaustiva. Além da consulta ao catálogo de autoridades da LC, os profissionais buscam fontes brasileiras e estrangeiras e, quando possível, o contato com o próprio autor para consolidação dos dados. Desta forma, o máximo de rigor é exigido para que a qualidade dos registros seja uma constante.

InCID: R. Ci. Inf. e Doc., Ribeirão Preto, v. 1, n. 2, p. 77-88, jul./dez. 2010 
De um modo geral, os esforços para manter o padrão de qualidade esperado de uma Agência Bibliográfica Nacional têm sido recompensados através do retorno dos usuários. Muitos escrevem apontando incorreções, outros enviam dados para complementar os registros já disponíveis, e não faltam aqueles que simplesmente escrevem para registrar que utilizam os bancos de dados, para felicitar pelo trabalho, ou para pedir esclarecimentos.

\section{Considerações Finais}

Embora o corpo deste texto esteja muito próximo de um grande lamento, o objetivo é mais o de apresentar a realidade da maior biblioteca da América Latina, desconhecida de grande parte dos profissionais bibliotecários do país. Esperamos que a divulgação destas informações chame a atenção para a delicada situação da cultura brasileira, grandemente representada pelo acervo que a Fundação Biblioteca Nacional se encarrega de armazenar e tratar.

Acreditamos que é necessário um esforço coletivo em prol da identificação e implantação de soluções concretas, que amenizem os problemas e apontem meios de colaboração entre as instituições e os profissionais, nos mais diversos âmbitos. Ressaltamos que esta colaboração é não só necessária como preconizada por todos os instrumentos sobre os quais discorremos aqui: afinal, o controle bibliográfico nada mais é do que um sonho da classe bibliotecária que pode, com o empenho comum, tornar-se mais próximo da efetividade. Com isso, garantimos nossa parcela de contribuição no desenvolvimento científico, tecnológico e social da humanidade. A Fundação Biblioteca Nacional, apesar de todas as dificuldades, trabalha com afinco para promover este ideal e não se furta de cumprir a sua missão de ser, em última instância, a casa do bibliotecário brasileiro. 


\section{Referências}

CAMPELLO, Bernadete. Introdução ao controle bibliográfico. 2. ed. Brasília: Briquet de Lemos, 2006.

FONSECA, Edson Nery da. Bibliografia Brasileira Corrente: evolução e estado atual do problema. Ciência da Informação, Brasília, v. 1, n. 1, p. 9-14, 1972.

IFLA Core Activity: IFLA-CDNL Alliance for Bibliographic Standards (ICABS). 2008. Disponível em: <http://archive.ifla.org/VI/7/icabs.htm>. Acesso em: 19 jul. 2010.

KNUTSEN, Unni; MOVILLA LOPEZ, Francisca. Survey on the state of national bibliographies in Latin America. 2004. Disponível em:

$<$ http://archive.ifla.org/VII/s12/pubs/s12-national-bibliography-latinamerica.pdf>. Acesso em: 06 jul. 2010.

LARIVIÈRE, Jules. Guidelines for legal deposit legislation: a revised, enlarged and updated edition of the 1981 publication by Dr. Jean Lunn. Paris: Unesco, 2000. Disponível em: < http://unesdoc.unesco.org/images/0012/001214/121413Eo.pdf>. Acesso em: 08 jul. 2010.

\section{Bibliografia Consultada}

DEPÓSITO legal. 2009. Disponível em: <http://pt.wikipedia.org/wiki/Depósito_legal>. Acesso em: 08 jul. 2010.

IFLA Study Group on the Functional Requirements for Bibliographic Records. Functional Requirements for Bibliographic Records: final report. 2009. Disponível em: <http://www.ifla.org/VII/s13/frbr>. Acesso em: 01 jul. 2009.

JOINT Steering Commitee for Development of RDA. A Brief Story of AACR. 2009. Disponível em: <http://www.rda-jsc.org/history.html> Acesso em: 19 jul. 2010.

MONTEIRO, Cristiane dos Santos. Sistemas de alimentação de catálogos e bases de dados. Marília, 2003. Disponível em:

$<$ http://www8.fgv.br/bibliodata/indexmodelo.asp?modelo=textos.htm>. Acesso em: 05 jul. 2010 . 